\title{
JACQUES MARITAIN Y RAYMOND ARON \\ SOBRE EL MAQUIAVELISMO (1934-1982): \\ UN MOMENTO MAQUIAVÉLICO FRANCÉS
}

\author{
Jacques Maritain and Raymond Aron \\ on machiavellianism (1934-1982): \\ A French machiavellian moment
}

\author{
JERÓNIMO MOLINA CANO \\ Universidad de Murcia \\ jeromo@um.es

\begin{abstract}
JESÚS A. GUILLAMÓN AYALA
Universidad de Murcia

jesusadolfo.guillamon@um.es
\end{abstract}

Cómo citar/Citation

Molina Cano, J. y Guillamón Ayala, J. A. (2017).

Jacques Maritain y Raymond Aron sobre el maquiavelismo (1934-1982):

un momento maquiavélico francés.

Revista de Estudios Políticos, 176, 281-307.

doi: https://doi.org/10.18042/cepc/rep.176.09

Resumen

Jacques Maritain, filósofo católico y teólogo de la política, y Raymond Aron, filósofo laico y sociólogo político, inician en 1939 una querella sobre el maquiavelismo - episodio altamente significativo del llamado «momento maquiavélico francés»-, la cual, con periodos de silencio, alcanza los años ochenta. Este artículo propone una lectura original de esa polémica con el trasfondo de la Segunda Guerra Mundial. La conclusión es que Maritain, en contra de las apariencias y una opinión muy extendida, no es un antimaquiavelista hipermoralista, sino más bien un maquiavelista disimulado, según el arquetipo de los escritores políticos católicos de la Contrarreforma. Tampoco Aron es un liberal neorrepublicano, mucho menos un neoliberal, sino un realista político partidario de un maquiavelismo moderado. 


\section{Palabras clave} francés.

Jacques Maritain; Raymond Aron; maquiavelismo; momento maquiavélico

\section{Abstract}

In 1939, Jacques Maritain, catholic philosopher and theologian of politics, and Raymond Aron, secular philosopher and political sociologist, initiated a dispute regarding Machiavellianism that continued until the 1980s. The dispute constituted a highly significant episode in the so-called «French Machiavellian Moment». This article proposes an original reading of this controversy in the context of World War II. Our conclusion is that, despite appearances and widespread opinion, Maritain was not a mere anti-Machiavellist or hyper-moralist political thinker, but rather a covert Machiavellist political writer in keeping with the archetype of Catholic political writers of the Counter-Reformation. Similarly, Aron is not a neo-republican liberal, much less a neoliberal, but a political realist thinker who advocates a moderate Machiavellism.

\section{Keywords}

Jacques Maritain; Raymond Aron; machiavellianism; French machiavellian moment. 


\section{SUMARIO}

I. EL «MOMENTO MAQUIAVÉLICO FRANCÉS». II. RAYMOND ARON Y JACQUES MARITAIN: EN DIVERGENTE ACUERDO. III. UN DEBATE SOBRE LO ESENCIAL DE LO POLÍTICO. 1. Maritain 1934-1938: No ceder a la infiltración del espíritu maquiavélico. 2. Aron 1939: Demócratas, sed capaces de las virtudes totalitarias. 3. Maritain 1940-1941: El maquiavelismo absoluto aplasta el maquiavelismo moderado. 4. Aron 1943: No siempre se pueden elegir los medios de la acción política. 5. Maritain 1943-1945: Es moralmente lícito represaliar al enemigo por sus abominaciones. 6. Maritain 1951: La fuerza suprema está en la justicia. 7. Aron 1982: No se puede prescindir del maquiavelismo moderado. IV. DE MASTINES Y ZORROS. 1. La guerra de España y la batalla de Francia en el compromiso políitico mariteniano. 2. La imaginación del desastre aroniana. BIBLIOGRAFíA.

Un agneau entreprend d'imposer aux loups sa manière de voir. Jacques Maritain, Religion et culture (1930).

El objeto de este estudio, continuación de otros anteriores sobre el realismo político (Molina Cano, 2015a; 2014)를 es la presentación de las posiciones de Jacques Maritain (1882-1973), filósofo católico in primis, teólogo de la política y escritor «hamletiano» (Molnar, 1999), y Raymond Aron (19051983), filósofo político, sociólogo y «espectador comprometido» (Aron, 1992a), con respecto a los medios lícitos de la acción política. Para ello se analiza su diálogo, debate de una extraordinaria densidad, aunque entrecortado y con síncopas, que como tal se extiende desde 1939 , si no antes $(1934)^{2}$, hasta 1982, desaparecido ya entonces el filósofo católico.

1 Sobre la concepción europea del realismo político hay dos textos recientes de gran interés: el de Luis R. Oro Tapia y el coordinado por Alessandro Campi y Stefano de Luca, este último una verdadera enciclopedia sobre el asunto (Oro Tapia, 2013; Campi y De Luca, 2014).

2 Maritain presenta de un modo casi sistemático su doctrina sobre el maquiavelismo en sus célebres lecciones de la Universidad Internacional de Santander en 1934, recogidas y ampliadas dos años después en Humanisme intégral (Maritain, 1947). 


\section{EL «MOMENTO MAQUIAVÉLICO FRANCÉS»}

La querella sobre el maquiavelismo ventilada por Jacques Maritain y Raymond Aron durante más de cuarenta años es una disputa sobre los medios políticos morales y justos. Su contexto inmediato en los años treinta es el de la discusión sobre la eficacia política del pacifismo y también, imposible ignorarlo a estas alturas, el de los primeros atisbos de la dimensión religiosa o pseudorreligiosa del totalitarismo ${ }^{3}$. Así pues, desde finales de los años veinte, aunque la terminología varía, se convierte en un lugar común la noción de "religión política» y no digamos ya durante la Segunda Guerra Mundial. Detalle que se suele pasar por alto, si bien aquí y allá se registran expresiones equivalentes que los autores más dispares apuntan en sus textos, ocasionales o no, con absoluta naturalidad. Además de las señaladas en otro lugar (Molina Cano, 2013a: 77) se podrían documentar muchas otras a voleo: Antoine de Saint-Exupéry, Gaston Bouthoul, el propio Maritain y, por supuesto, Aron (Saint-Éxupery, 2000: 175; Bouthoul, 1948: 138, 158; Maritain, 1937: 119; 1945a: 169; Aron, 1990b; 1953: 136). Louis Rougier se refiere con toda tranquilidad a las «nuevas religiones laicas» (Rougier, 1929) y Denis de Rougemont, pocas fechas después, a la clave interpretativa religiosa de la política contemporánea (De Rougemont, 1968: 319-320). El papa Pío XI denuncia en su encíclica Quas primas «una cierta religión natural» cuyo designio es sustituir a la religión de Cristo. Todavía no se ha escrito la historia de todas estas religiones intramundanas, epifanías sin Dios o ateologías políticas que, como recuerda Dalmacio Negro, tienen su origen en el «silencio de Dios» ${ }^{4}$.

Ello no obstante, la cuestión del maquiavelismo en Francia durante el siglo XX, espoleada por la crisis de la Tercera República francesa y la experiencia terrible de las dos guerras mundiales, presenta cierta autonomía. Según el oportuno calco de Serge Audier, puede hablarse de un «momento maquiavélico francés» (Audier, 2005: 7; Pocock, 2008), caracterizado por la vuelta a Maquiavelo de la filosofía política y la renovación del análisis del conflicto. Es mérito indudable de Audier la develación de un «momento» casi desconocido de las letras políticas francesas. No obstante, prima en su investigación el aspecto filosófico o politológico del problema del maquiavelismo ${ }^{5}$, quedando

3 Constituye una referencia imprescindible la obra de Emilio Gentile (Gentile, 2001).

4 Cuando Dios calla o no es escuchada su voz, el poder busca entonces legitimarse en una religión inmanente (Negro Pavón, 2009: 545 y 547). En el mismo sentido se expresaba Maritain al recalcar que «declararle la guerra a Dios es en sí mismo un acto de religión» (1937: 107).

5 «Una de [mis] hipótesis es que el regreso francés a Maquiavelo da una respuesta al estancamiento de la doctrina marxista [...], abriendo una vía [...] al redescubrimiento de lo político» (Audier, 2005: 31). 
generalmente en un segundo plano su dimensión existencial y política de una nación en decadencia.

El debate francés sobre el maquiavelismo invita a pensar las condiciones de una articulación entre conflicto y consenso en la perspectiva de los ideales in fieri de la modernidad democrática (Audier, 2005: 34). Estudia Audier la vuelta a Maquiavelo y las cuestiones anejas del maquiavelismo y el realismo político en Raymond Aron, en Claude Lefort y en Maurice Merleau-Ponty. Serge Audier se ocupa incidentalmente de la controversia entre Maritain y Aron (Audier, 2005: 71-84; Molina, 2013a: 47-59) . No obstante, Maritain merecería en ese libro capítulo aparte, pues su reflexión sobre el maquiavelismo es una de las constantes de su obra política anterior o posterior a 1927. Se echa también en falta a Charles Benoist y Julien Freund, para citar dos escritores políticos de los dos confines del siglo pasado que, por lo demás, ni mucho menos desentonan en la polémica de Maritain con Aron. Charles Benoist (1907-1936) constituye una fuente directa para ambos. Julien Freund, discípulo de Aron, es el más maquiaveliano de los escritores políticos franceses del siglo XX; antes de su encuentro con Carl Schmitt ha debido ser un lector atentísimo del Maritain filósofo político que habla, como él mismo, de la «esencia de lo político», del «bien común como finalidad de la política», de la "realización de las esencias y su combinatoria en la historia», de la «jerarquía de las esencias» y de una "política [auténticamente] política» (Maritain, 1941a: 53; 1945a: 165; 1947: 224; 1926: 31; 1941b: 136; Freund, 1986; 1987).

\section{RAYMOND ARON Y JACQUES MARITAIN: EN DIVERGENTE ACUERDO}

Los textos de Raymond Aron sobre el maquiavelismo han suscitado desde su publicación en los años noventa el interés de los estudiosos aronianos, particularmente de quienes, partidarios y custodios de un Aron liberal sociólogo y teórico de las relaciones internacionales, políticamente neutralizado hasta cierto punto, forman su guardia de corps intelectual en Francia. Los problemas teóricos y prácticos planteados por las formas atenuadas del maquiavelismo, que Aron acepta ciertamente como realista político, han incoado una controversia sobre la ambigüedad de Aron en este punto, todavía no desarrollada a pesar de su interés.

6 Algún otro escritor ha presentado también, con mayor o menos amplitud, la querella Aron-Maritain (Molina Cano, 2015b; Tabet, 2013: 259-260). Con todo, se trata de un asunto que dista de estar agotado. 
La crítica del maquiavelismo en Jacques Maritain ha sido también estudiada por diversos especialistas, entre los cuales se destacan Erich Kussbach, James V. Schall, Gonzalo F. Fernández, Jason Blahuta y Gladys L. Portuondo (Kussbach, 1991; Schall, 1998; 1999; Fernández, 2004; Blahuta, 2008; Portuondo, 2009). Todos ellos ponderan el antimaquiavelismo de Maritain, tesis de la que aquí nos vamos a apartar, pues su antimaquiavelismo, servata distantia, no difiere, en última instancia, del maquiavelismo disimulado de ciertos tratadistas católicos de la Contrarreforma. Por otro lado, ninguno de los estudiosos maritenianos ha considerado su divergencia con Aron. Curiosamente, no hay ni una sola referencia a R. Aron en los importantes trabajos que Piero Viotto ha dedicado a la obra y a las amistades de Maritain (Viotto, 2003; 2009).

No puede ignorarse la divergencia intelectual entre Maritain y Aron, pues ello, después de todo, aunque otra cosa parezca, subraya una cierta convergencia de fondo en su diálogo de años sobre el maquiavelismo. La misma que pone de manifiesto Aron en sus consideraciones de 1982 sobre ese mismo diálogo. Aron, un maquiavelista templado, y Maritain, un católico que tal vez afecta ignorar su propio maquiavelismo, ambos franceses de la Francia Libre y, con sus reservas relativas, partidarios de De Gaulle, no se encuentran finalmente tan lejos. De hecho, los dos provenían intelectualmente del republicanismo laico de la Tercera República, que les deja su marca indeleble. El primero se forma en el ambiente normalien del liceo Henri IV. Aron, estudiante del liceo Condorcet, solo por razones prácticas, encuentra en Alain, profesor del Henri IV, al maître à penser de su juventud. Maritain, apadrinado por Léon Bloy, se convierte al catolicismo en 1906 y navega muy cerca de L'Action Française hasta 1927. Aun así, Maritain nunca ha dejado de ser "por temperamento, lo que llamamos un hombre de izquierdas» (Maritain, 1966: $40)^{7}$. En cuanto a Aron, en 1940 ya no queda en él ni rastro del idealismo irenista inculcado por Alain, aceptando gustoso ser tratado de «anticomunista sistemático e implacable» (Aron, 1983: 737). Pero este detalle no cuenta entre quienes, a pesar de no haberse encontrado personalmente sino una vez en toda su vida ${ }^{8}$ y haber mantenido, según parece, una breve relación epistolar (Aron, 1993c: 426), se reconocen mutuamente su valía.

7 El término «izquierda» resulta problemático en Maritain. En un hombre cuya sensibilidad política se forma bajo la Tercera República, «ser de izquierdas» significa, más bien, participar de los principios políticos de la tradición republicana francesa.

8 Raymond Aron no recordaba en 1982 haber llegado a tratarle en persona («he leído una parte de su obra, pero nunca coincidimos»). En realidad, por lo que señala en sus memorias, tuvo que conocerle sin duda en una sesión de la Sociedad Francesa de Filosofía celebrada pocas semanas antes de que empezara la guerra (Aron, 1983: 157; 1993a: 189-191). 


\section{UN DEBATE SOBRE LO ESENCIAL DE LO POLÍTICO}

Maritain y Aron inician su diálogo el 17 de junio de 1939. Aron disertó en la Sociedad Francesa de Filosofía sobre la contraposición de los Estados democráticos y los totalitarios en punto a sus élites, a la naturaleza ideológica y económica de sus conflictos diplomáticos, al carácter conservador o revolucionario de unos u otros, a los éxitos en todos los órdenes de los segundos y a la presunta fatalidad de la disyuntiva comunismo o fascismo para las democracias (Aron, 1993a). Tras el diálogo subsiguiente acerca de las virtudes heroicas y los medios violentos que los regímenes democráticos pueden utilizar para defenderse de sus enemigos sin convertirse en especies políticas totalitarias apuntan diferencias importantes, si bien la impresión de Aron es que Maritain, "que no pertenecía a [su] generación[, le] daba su asentimiento» (Aron, 1983: 157). Como se señala a continuación, la posición de Maritain en ese momento, que anticipa el contenido fundamental de su juicio de 1941 sobre Maquiavelo y el maquiavelismo, es la misma ya expuesta sumariamente por él en una conferencia dictada en el teatro Marigny de París el 8 de febrero de 1939 (Maritain, 1941a). Ni la intervención en la Société Française de Philosophie ni la conferencia mencionadas alteran sustancialmente su doctrina sobre el maquiavelismo expuestas en 1934 en sus famosas lecciones españolas sobre los «Problemas espirituales y temporales de un nuevo cristianismo» (Maritain, 2000a; 1947).

Pero los argumentos centrales del diálogo se intercambian entre noviembre de 1940, fecha en la que Maritain firma en Nueva York el prefacio del combativo À travers le désastre (1942b) y julio de 1943, ocasión del artículo que Aron publica en La France Libre a propósito del texto que Maritain dedica expresamente a la querella de los contemporáneos sobre el maquiavelismo (1942a; 1942b; 1945a: 151-206).

El 26 de septiembre de 1941, con ocasión del cincuenta aniversario de la Universidad de Chicago, Maritain es invitado a participar en unas jornadas sobre «El lugar de la ética en las ciencias sociales» presididas por el historiador John Ulric Nef. El contenido de la comunicación, revisada y escrita en inglés, se convierte al año siguiente en "The End of Machiavellianism», artículo recogido por The Review of Politics, la revista de Waldemar Gurian (Maritain, 1942a). La traducción francesa del mismo texto (Maritain, 1942b), publicada por Nova et Vetera, la revista del teólogo y futuro cardenal Charles Journet, sirve más tarde de base para el capítulo quinto de Principes d'une politique humaniste (Maritain, 1945a).

La reacción de Aron a la versión inglesa, firmada bajo seudónimo (René Avord), se publica en un artículo aparecido en La France Libre, la revista de los franceses exiliados en Londres, el 15 de julio de 1943: «Pensée française en exil 
(II): Jacques Maritain et la querelle du machiavélisme» (Aron, 1993b). Maritain dirige entonces la colección «Civilisation», publicada en Nueva York por Éditions de la Maison Française y que planea ofrecer L'homme contre les tyrans, de Raymond Aron (1990a); le agradece a Aron la agudeza de su crítica y le responde expresamente en una nota que incluye en el capítulo «El fin del maquiavelismo" del ya citado Principes d'une politique humaniste (Maritain, 1945a: 197-198). En ella muestra su acuerdo con Aron en lo sustancial, pero no deja de subrayar su discrepancia.

En diciembre de 1949, bajo los auspicios de la Charles R. Walgreen Foundation for the Study of American Institutions, dicta Maritain seis conferencias en la Universidad de Chicago que se convertirán en la gran síntesis tardía del pensamiento político mariteniano: The Man and the State (Maritain, 1953). En el capítulo tercero, dedicado al problema de los medios, vuelve al problema el maquiavelismo para subrayar que el respeto a la justicia no está reñido con la fortaleza.

Más de treinta años después, invitado por la Société des Amis de Jacques Maritain a la conferencia celebrada en la Unesco para conmemorar el centenario del nacimiento del filósofo, fallecido en Toulouse en 1973, Aron continúa el diálogo in absentia. «Se me pide continuar hoy el diálogo con Maritain, a pesar de que mi interlocutor ya no está con nosotros. A él mismo le habría parecido perfectamente legítimo prolongar una discusión que, sin duda, toca lo esencial: lo esencial de la política, lo esencial de la acción política, lo esencial en suma de su propio pensamiento» (Aron, 1993c: 427).

\section{MARITAIN 1934-1938: NO CEDER A LA INFILTRACIÓN DEL ESPÍRITU MAQUIAVÉLICO}

La meditación mariteniana sobre el maquiavelismo está en todos sus escritos políticos (Aron, 1993b: 386) y forma parte de su crítica de la modernidad, particularmente del acontecimiento en ella central: el humanismo antropocéntrico. De algún modo, Maquiavelo es el capítulo que le falta a su libro sobre los tres novatores del espíritu moderno: Lutero, Descartes y Rousseau (Maritain, 1948).

Maquiavelo es, pues, otro «reformador». Si el cartesianismo es el pecado francés en la historia de la inteligencia, y el luteranismo, el alemán (Maritain, 1925: 123), bien puede decirse que el maquiavelismo es el pecado italiano. No obstante, el «fisicismo político» (Maritain, 1930: 43-45), sinónimo de maquiavelismo, es también consecuencia del espíritu cartesiano («un ángel que conduce una máquina»), según el cual es políticamente bueno lo que propicia el éxito material y la potencia del Estado. Frente al maquiavelismo que explota los hechos, los retuerce y extirpa de ellos toda trascendencia, lo 
que importa es soportar la prueba (Maritain, 1927: 79). Dios golpea para vivificar y en la tribulación envía su gracia. El ojo providencialista del filósofo "descubre debajo de la ruina y la corrupción [...] germinaciones preciosas» (Maritain, 1925: 217). Deus screve direito por linhas tortas, según el proverbio portugués que Maritain recoge en uno de sus libros (1930: 33). Perder con armas puras es ganar, pues también así se manifiesta la Providencia divina (ibid.: 71).

En el curso de la Universidad de Santander impartido por Maritain en el verano de 1934 se examina el maquiavelismo como factor que impide la realización del ideal histórico concreto de la nueva cristiandad. Además del economicismo, Maritain discurre sobre el politicismo y el modo de superarlo y trascenderlo. Este politicisme trascendé presupone una idea puramente técnica de la política: la actividad política como actividad amoral, los hechos sociales como simples hechos físicos, el saber político como una técnica. Si hubiera que nombrar esta "concepción politicista", concluye Maritain, bien podría vincularse "con el gran escritor y heresiarca político de los tiempos modernos: Maquiavelo" (1947: 218). Aun así, como todo error contiene su parte de verdad, la "verdad del maquiavelismo» está en su saludable reacción contra el supermoralismo, una falsa concepción de la ética, «una moral farisaica, puramente formal y geométrica que reniega de la naturaleza y la vida» (ibid.: 218219). Se refiere, evidentemente, a la moral kantiana, incapaz de reconocer la especificidad de la ética política. De hecho, el supermoralismo constituye la gran coartada del maquiavelismo, pues atribuyendo a la política un purismo impracticable justifica «el rechazo de la moral como condición existencial de toda política» (ibid.: 222). "Se impone de este modo a una política amoral unas reglas morales apolíticas" (ibid.: 225). No se puede explicar mejor la explotación maquiavelista de la ética?.

Maritain aspira a formular un realismo auténtico e integral, polo opuesto del «cinismo sin inteligencia de la Realpolitik» (2013: 9). Este último constituye en realidad un "pseudorrealismo" nocivo. Hay un pseudorrealismo banal de los hombres prácticos que confían en la fuerza y actúan por impulsos. Su éxito es efímero, pues no arraiga en la historia. Más consistente y profundo y, por tanto, más peligroso, es el "pseudorrealismo maquiavélico». Este

9 Como puede apreciarse en las últimas páginas de Principes d'une politique humaniste, el repudio del maquiavelismo en Maritain no puede separarse de su no menos crítica disección del moralismo político. Maritain no evita «la mortal antinomia entre la ética y la política generada por los maquiavelistas y los hipermoralistas», sino que pretende sortearla afirmando al mismo tiempo que «la política es esencialmente moral y la ética esencialmente realista» (Maritain, 1945a: 201). 
"convierte ciertas verdades empíricas en mentiras ontológicas», pues arranca a la persona de la trascendencia y la pone bajo la custodia del Estado, que hace las veces de Dios para poner coto a la peligrosidad del hombre (Maritain, 1947: 229-230).

En su conferencia sobre «El crespúsculo de la civilización», del 9 de febrero de 1939, Maritain denuncia la dimensión religiosa del comunismo soviético y del nacionalsocialismo, doctrinas maquiavélicas que son consecuencia de la crisis del humanismo moderno y de la separación, en él operada, entre Dios y el mundo y que abandona la política a su «ley carnal» (Maritain, 1941a: 45-46). La raíz del maquiavelismo está en un concepto de la política como "regla y medida supremas» (ibid.: 51). Lo hace posible un "contrahumanismo racionalista y noble» que finalmente es arrastrado por la tremenda conmoción del «contrahumanismo irracionalista y servil» (ibid.: 19-23). El peligro para las democracias es palmario, pues el democratismo, una forma de pseudorrealismo, idealista y cínico al mismo tiempo, que tiene su origen en Rousseau (Maritain, 1947: 231), ha alterado las virtudes democráticas de inspiración cristiana. Acosadas por la propaganda, por los éxitos y por la unanimidad de las dictaduras totalitarias, seguidoras de Maquiavelo y adictas a «su principio político: la fuerza y la astucia», las democracias deben dejarse reorientar por el humanismo cristiano, no amputado de la ética. Un «humanismo de la Encarnación», base de un "renacimiento espiritual» (redressement spirituel) inasequible a la «infiltración del espíritu totalitario» (Maritain, 1941a: 27, 88 y 92).

\section{ARON 1939: DEMÓCRATAS, SED CAPACES DE LAS VIRTUDES TOTALITARIAS}

Aleccionado por el derrumbamiento de la República de Weimar y convertido al realismo político (Aron, 1993e), como él mismo reconoce, Raymond Aron, «espoleado por los acontecimientos», se ocupa de Maquiavelo y del maquiavelismo a partir de la primavera de 1937 (1983: 152). Comienza a elaborar un libro del que solo se publicarán, póstumamente, cuatro fragmentos dedicados al maquiavelismo de Maquiavelo y Pareto (Aron, 1993f; 1993d), a la comparación de Maquiavelo y Pareto (1993g) y a la relación entre el maquiavelismo y las tiranías totalitarias (1993h). Se registran en ellos algunas nociones que después alcanzan una posición vertebradora de su filosofía de la política, particularmente la noción del primado de lo político (1993d: 114) y la caracterización del realismo político como una doctrina política en la que prima la observación sobre la ética (1993f: 63).

Reconciliado más tarde con estos escritores clásicos, susceptibles de las más diversas lecturas — fascista, elitista, liberal y escéptica o cínica (Aron, 1993i) —, esas críticas páginas redactadas a finales de los años treinta no 
pierden en absoluto su interés, sino que más bien lo acrecientan por quedar en ellas incoada la aplicación de la noción «maquiavelismo» al estudio del totalitarismo nacionalsocialista. Una vez depurada su caracterización del maquiavelismo, precisamente en el desarrollo de la querella con Maritain, Aron fija una segunda categoría, la religión secular o religion séculière, aplicada especialmente al análisis del marxismo-leninismo (1990b: 925-948). Comoquiera que "la religión secular [...] es una forma de maquiavelismo despiadado» (ibid.: 926), la comunidad de sentido entre uno y otra es plena (Molina Cano, 2013a). Se trata de dos maneras de abordar las formas inauditas del despotismo contemporáneo. Mas pesa todavía sobre el ánimo de Aron la leyenda negra del Florentino, responsable para muchos de una "teoría de la barbarie» (Aron, 1993j: 201). Esta es también la impronta algo elemental que Maquiavelo ha dejado en su minerva: el maquiavelismo es el arte de gobernar mediante el terror.

Ahora bien, la repentina actualidad de Maquiavelo no es casual, sino que está llena de sentido para unas democracias que viven un «tiempo maquiavélico». Para vencer al enemigo es necesario comprenderlo, pues «no hay en la historia un ejemplo de una empresa imperialista que, después de haber sido anunciada y anticipada con tanto estrépito, haya sorprendido más a sus víctimas» (Aron, 1993j: 202) ${ }^{10}$. En un artículo firmado bajo seudónimo (René Avord) y publicado en 1940 en La France Libre se aventura a deducir de El principe y los Discursos de Maquiavelo «ciertas reglas desconocidas por nuestros gobiernos y aplicadas por nuestros enemigos" (ibid.: 192). De modo que "para tomarle la medida a la conducta y a los proyectos del enemigo conviene adoptar su manera de pensar y de referirse a la técnica aplicable a los casos concretos» (ibid.: 202). En este pasaje escrito en el exilio se registra una dimensión utilitaria mucho más acentuada que en los fragmentos elaborados hasta la fulminante derrota de Francia. El maquiavelismo de sus reflexiones es un maquiavelismo por necesidad.

Pero la batalla de Francia no es el catalizador de la segunda y definitiva etapa de su conversión al realismo político, al menos no el único. Debió tener también su importancia en este proceso el desconcierto político de la Tercera República a partir de los acuerdos de Múnich del 30 de septiembre de 1938. En esa atmósfera tan cargada, a menos de tres meses del estallido de la Segunda Guerra Mundial, el 17 de junio de 1939, lee Raymond Aron una comunicación ante la Société Française de Philosophie titulada «États démocratiques et

10 Son muchos los que por entonces caen en la cuenta de que la doctrina nacionalsocialista no era clandestina ni se disimulaba, sino que se recogía a las claras en Mein Kampf de Hitler (Maritain, 1941b: 37; Churchill, 2016: 101). 
états totalitaires» (1993a). Aunque se trata de un texto pegado a la realidad, es de una enorme densidad de página. Se entrecruzan en él dicotomías políticas trascendentales: democracia-totalitarismo, revolucionarismo-conservadurismo, intervencionismo económico-liberalismo o racionalismo-irracionalismo, cuyo tratamiento deja estupefacto a una parte del auditorio, en el que se encuentra Jacques Maritain.

Aron debía ser consciente de que ponía a prueba las convicciones pacifistas de los filósofos de la generación anterior con afirmaciones como esta, a la sazón el detonante del diálogo con Maritain: «Las democracias no pueden justificarse limitándose a invocar unos valores que sus enemigos desprecian, sino que deben mostrarse capaces de las virtudes cuyo monopolio reclaman los regímenes totalitarios» (Aron, 1993a: 174). El filósofo Victor Basch, por ejemplo, muestra en su intervención un desacuerdo absoluto «revestido de patetismo». A su juicio, las democracias han triunfado siempre, de modo que el pesimismo aroniano, lejos de alimentar la fe democrática, la destruye.

Dice Aron que frente a los regímenes que alardean de la fuerza resulta de lo más ridículo parlotear perpetuamente sobre el pacifismo. «Es grotesco creer que se resiste a los cañones con la mantequilla, a la acometividad con el reposo" (Aron, 1993a: 184-185). Juzga indispensable que las democracias occidentales afirmen su capacidad de heroísmo y reconstituyan la élite dirigente. Aconseja adoptar también ciertas medidas técnicas de los denostados regímenes totalitarios, en particular algunas de sus disposiciones de política demográfica, económica y social (ibid:: 186).

Maritain le planteará una objeción de fondo: si se adoptan las virtudes y técnicas totalitarias para resistir a los totalitarios «nos convertiremos en eso» (ibid:: 189). Pues una cosa es aceptar una guerra si esta es necesaria y otra cosa muy distinta aceptar los medios totalitarios allanándose ante su eficacia. Como dirá ya en plena guerra, un Estado acosado por enemigos maquiavélicos debe acrecer sus fuerzas físicas y morales, pero no debe caer en las fáciles soluciones del maquiavelismo, pues entonces estaría añadiendo a sus debilidades «un principio letal» (Maritain, 1945a: 188). Aron, en su respuesta, no es tan pesimista sobre el riesgo, sin duda cierto, de infestación totalitaria. «Para sobrevivir en el orden de la historia hay que consentir el empleo de medios eficaces, pues solo con armas se resiste a las armas» (Aron, 1993a: 189).

\section{MARITAIN 1940-1941: EL MAQUIAVELISMO ABSOLUTO APLASTA EL MAQUIAVELISMO MODERADO}

La derrota sorprende a Jacques Maritain en los Estados Unidos, en donde se encuentra desde enero de 1940 para dictar varios cursos. Allí permanecerá casi toda la guerra contribuyendo al esfuerzo bélico con sus alocuciones 
radiofónicas (Maritain, 1945b), sus conferencias y sus libros para la propaganda de guerra y posguerra (Maritain, 1940; 1941b; 1945c). Crítico moderado del régimen de Vichy y contrario al liderazgo de De Gaulle en los primeros momentos, su voz se convierte súbitamente en una referencia de la Francia Libre y en una de las dos conciencias de la Francia transterrada (Aron, 2000: 12). La otra era Saint-Exupéry, el Herman Melville del aire ${ }^{11}$.

La Segunda Guerra Mundial no es una simple guerra nacional ni una guerra de policía ni una guerra santa, sino una «guerra por la civilización» (Maritain, 1941b: 50). Según Maritain, Occidente «está saldando [con ella] una cuenta acumulada por las faltas de toda la historia moderna» (1945a: 180). En À travers le désastre desaconseja una política eudeominista: «La autocrítica y el examen de conciencia no son las condiciones psicológicas más favorables para hacer la guerra» (1941b: 42). Francia necesita heroísmo, pues cuando todavía era posible no escogió una política intensiva de rearme y alianzas, combinada con una diplomacia que le permitiera ganar tiempo. Le parece indudable, como escribe más tarde, que el bien común exige en ocasiones el principio del mal menor y la tolerancia de males, cuya prohibición sería mucho más perniciosa que el mal consentido (1947: 233).

El diálogo con Aron en el París prebélico no tranquiliza a Maritain, si bien este se muestra de acuerdo con la severa advertencia del comunicante: «Es muy sencillo: los estados totalitarios están listos para combatir y, se reconozca o no, hasta que las democracias no lo estén también se encontrarán en inferioridad de condiciones, incluso morales» (Aron, 1993a: 191). Ahora bien, la elección de los medios que oponer al enemigo, puesto que en ellos se prefiguran los fines, es materia sumamente grave; tanto como para volver la mirada hacia Maquiavelo y desentrañar las razones de su actualidad.

En su estudio sobre "La fin du machiavélisme», a pesar de todo, escribe de Maquiavelo con cierta piedad. Dice de él cosas terribles. Le achaca, entre otras faltas y responsabilidades, tomar conciencia de la fecundidad del mal, que en lo sucesivo podrá ser explotado sin remordimientos por los príncipes (Maritain, 1945a: 153). Sobre un trasfondo de pesimismo, Maquiavelo, un rígido moralista, oculta la imagen de Dios en el hombre. Libera la acción de los príncipes de toda atadura moral y religiosa, infligiendo una violenta mutilación a la inteligencia política (ibid:: 154). Ahora bien, Maquiavelo no es un espíritu estúpido, sino todo lo contrario, «demasiado inteligente para no verse

11 Maltratado por muchos gaullistas, la traducción inglesa de su Pilote de guerre (1942): Flight to Arras, seguramente, hizo más en Estados Unidos por la causa francesa que À travers le desastre de Maritain (Lanux, 2000: 196-197; Saint-Exupéry, 1997: 186192, 208). 
a sí mismo sino como un cínico que explota el fondo moral de la tradición [cristiana]» (Maritain, 1941b: 123). El maquiavelismo de Maquiavelo, «su cruel operación», presupone la perduración y consistencia de la tradición por él ofendida. La tragedia del humanismo antropocéntrico es que su pretensión de enriquecer a la humanidad se paga malbaratando su herencia (Maritain, 1937: 106). Volatilizado ese fantástico patrimonio espiritual, dirá Maritain, solo queda un aparato monstruoso que persevera en el mal: «[...] esto es lo que se conoce por realismo político» (1941b: 124).

Pero una cosa es el maquiavelismo de Maquiavelo y otra el «maquiavelismo común» de muchos de sus adictos de todas las épocas. No obstante, los grandes estadistas nunca han perdido de vista el bien común como fin de la política. En este sentido, dice Maritain que se han comportado como maquiavelistas moderados, respetables y conservadores (1945a: 167). Aunque el maquiavelismo moderado (machiavélisme modéré) usa el mal con mesura y la injusticia dentro de límites razonables, su activismo franquea inexorablemente el camino al empleo utilitarista de medios odiosos explotados por una inteligencia vulgar. Es el maquiavelismo absoluto (machiavélisme absolu), menos sagaz y más inhumano que el de Maquiavelo. Este maquiavelismo ya no es una política, sino "una metafísica, una religión, un entusiasmo profético y místico» (ibid:: 169) ${ }^{12}$. Es la tragedia del maquiavelismo que termina en la muerte, «término de una evolución que ha vulgarizado, universalizado y hasta democratizado el maquiavelismo [de Maquiavelo]» (Maritain, 1940: 90). Antes de destruirse a sí mismo, el maquiavelismo absoluto arrambla con el maquiavelismo moderado (Maritain, 1945a: 170; 1941b: 134).

Por la inestabilidad interna y externa que lastra toda forma de maquiavelismo, el absoluto se convierte en el puerto de arribada del moderado. Maritain llama a esto "la paradoja del maquiavelismo». La extirpación del cerebro del príncipe de los valores morales es causa de la inestabilidad interna. Este amoralismo político fructifica en la medida en que opera sobre un ethos en el que los valores de los que reniega el príncipe mantienen su vigencia. Ahora bien, «un arte semejante consume y destruye su propia materia y, al mismo tiempo, degenera y se corrompe» (Maritain, 1945a: 164). Mas el desequilibrio congénito del maquiavelismo tiene también una causa externa, determinada por la dinámica de la política de potencia: los gobiernos más maquiavélicos destruyen a los que no lo son tanto. No se puede, pues, explotar impunemente el maquiavelismo. Se explica así Maritain la derrota de Francia. El maquiavelismo

12 Según Maritain, el maquiavelismo moderado es un arte, pero el absoluto es una ciencia natural que aplica presuntas «leyes científicas a la lucha por la vida de las sociedades humanas» (1945a: 168). 
trasmina el orden de la Tercera República, desbordada por las maniobras del «maquiavelismo ruso» (a través del Frente Popular) y por las del «pseudorrealismo de un pequeño maquiavelismo impotente», el de los sedicientes partidos del orden (Maritain, 1941b: 22-25). La burguesía tiene por ello una responsabilidad máxima en la derrota y precisamente Charles Benoist constituye un buen ejemplo del «honesto maquiavelista de la burguesía francesa» (ibid.: 137). Con un tono áspero denuncia Maritain que estos «desgraciados», promovieran el maquiavelismo, creyendo encontrar en él una guía segura ${ }^{13}$. Ninguno vio aparecer «el rostro feroz del maquiavelismo absoluto (machiavélisme absolu), del maquiavelismo insensato, triunfante sin esfuerzo sobre el maquiavelismo razonable (machiavélisme raisonable)» (ibid.: 126) ${ }^{14}$.

El maquiavelismo nunca triunfa, remacha Maritain, añadiendo a la paradoja una ilusión. Esta «ilusión del maquiavelismo», el espejismo de un éxito inmediato y arrollador como el de Alemania, la genera el desfase entre los actos políticos y su fructificación histórica (Maritain, 1940: 106-107). El mal no triunfa nunca porque se corrompe en la durée. Sus éxitos inmediatos y duraderos son solo aparentes ${ }^{15}$. Para nuestro desconcierto sucede que el mal madura antes que el bien. Según Maritain, se trata de una verdadera ley histórica: la «ley de las fructificaciones de las acciones humanas» (1945a: 186). Pero comoquiera que la durée politique, reflejo del gobierno divino y supremo de la historia (ibid.: 182), es superior al término de una vida humana, es posible que cuando el bien triunfe... la tierra se haya comido los ojos de los justos. Por eso, como adelanta ya en las páginas de $A$ travers le désastre, el triunfo del maquiavelismo constituye y al mismo tiempo anticipa su final, siquiera ante la conciencia de los pueblos. «Si la justicia no lo destruye, lo hará la muerte, la misma muerte que él ha extendido por todo el mundo y que es más fuerte que él» (Maritain, 1941b: 134-135). Dios puede

13 Del mismo modo, el «catolicismo no cristiano» (non-Christian Catholicism) de L'Action Française, al politizar maquiavélicamente la verdad eterna de la religión, forzosamente tenía que descarrilar (Maritain, 1942c: 271).

14 Es la primera vez que Maritain distingue dos maquiavelismos (absoluto y moderado), nociones que amplía unos meses después. R. Freymond no tiene razón al atribuir a R. Aron «la noción desarrollada en 1943 de maquiavelismo moderado (machiavélisme modéré)» (1993: 14).

15 Maritain escribe sobre el fin del maquiavelismo en 1941. Cuando prepara la edición de Principes d'une politique humaniste incorpora esta nota al texto original: «Cuando releo estas páginas (septiembre de 1943) para enviarlas al editor, el mundo acaba de enterarse de la caída sin gloria de Benito Mussolini. Los triunfos de este miserable discípulo del maquiavelismo absoluto, pues no en vano escribió un prefacio a una edición de El príncipe, han durado veinte años» (1945a: 177). 
permitir la victoria del mal, pero la justicia triunfará siempre. En esto consiste, según Maritain, el fair play de Dios (Maritain, 1945a: 177).

\section{ARON 1943: NO SIEMPRE SE PUEDEN ELEGIR LOS MEDIOS DE LA ACCIÓN POLÍTICA}

Raymond Aron llega a Inglaterra vía San Juan de Luz, puerto en el que consigue embarcarse, junto a una división polaca, en el transatlántico Ettrick. En Londres, redactor de La France Libre, traduce y escribe artículos y editoriales para la revista (Aron, 1983: 161-173). En el verano de 1943 llama la atención sobre dos franceses del exilio: Georges Bernanos y Jacques Maritain. Les dedica sendos artículos — «Pensée français en exil»— en los que destaca la contribución de estos escritores católicos a la literatura que no se resigna ante la debacle. En el primero de ellos, el de Bernanos, equipara la Lettre aux anglais de este, publicada en Brasil en 1942, con À travers le desastre de Maritain. Los dos libros le parecen custodios del honor de Francia, pero Aron hace también de ellos otra lectura. Esas páginas y muchas otras: Scandale de la vérité y Nous autres, Français, sin ir más lejos, textos de Bernanos, reflejan la intensidad con la que los franceses del exilio han discutido el problema del maquiavelismo. Les incita a ello el «realismo de Maurras», educador de una élite burguesa "con moral, pero sin mística», pretendidamente realista. Esa burguesía es el arquetipo histórico responsable de la destrucción de Francia y de la instauración en ella de una jerarquía basada en el dinero (Aron, 1994: 916) ${ }^{16}$. A juicio de Aron, no obstante, existe una diferencia sustancial entre Bernanos y Maritain, pues el primero escribe más como profeta que como filósofo, limitándose a mostrar la bajeza espiritual de sus enemigos, mientras que el segundo, movido igualmente por la pasión, multiplica argumentos y razones (Aron, 1993b: 385). El artículo sobre la querella del maquiavelismo es su reacción al artículo de Maritain publicado en The Review of Politics (Maritain, 1942a), pero también una continuación del diálogo que la guerra suspendió y ahora se presenta bajo una nueva luz.

16 No es casual que Maritain y Bernanos sean dos antiguos maurrasianos desafectos. Serge Audier no ha reparado en la centralidad que Charles Maurras tiene en ese drama en el que a Francia le va la vida. No se ocupa pues del maquiavelismo como problema político existencial y sangrante, sino más bien como asunto intelectual. A Maurras se le cita de pasada y una sola vez; a Bernanos, autor en 1939 de dos libros imprescindibles para este asunto, ninguna (Audier, 2005: 36; Bernanos, 1984). En cambio, el libro de Paul Sérant sobre los disidentes de L'Action Française sí que da algunas pistas (Sérant, 1978: 122-137). 
Expone Aron la doctrina mariteniana sobre el maquiavelismo o, más bien, sobre el antimaquiavelismo, que consiste en el rechazo de la política como un arte amoral que persigue el poder, única medida de su éxito, y de la explotación del mal. Aron reconoce que esta tesis puede ser admitida tanto por creyentes como por no creyentes, pero no oculta que su presupuesto es una "conversión que restituya a la política [...] su sentido espiritual» (1993b: 388). Así pues, la «superación del maquiavelismo» supone el reconocimiento de la política como un aspecto de la vida humana de la que aquella no puede ser arrancada, pero que, del mismo modo, no puede ignorar «los derechos imprescriptibles de la persona». Trascender el maquiavelismo significa también que el objetivo de una política humana no puede ser la potencia (ibid.: 391-392). ¿Acaso resuelve esta doctrina el problema práctico de un gobernante? De ninguna manera, pues queda en el aire el destino de la ciudad. Dice Maritain que el maquiavelismo nunca triunfa, pero esto tampoco es suficiente.

Los medios del político resueltamente hostil al maquiavelismo dependen de las circunstancias. Formula Aron algo parecido a una ley de hierro de la acción política: no siempre se pueden elegir los medios (1993b: 393). Maritain pretende que el fin de la política no es la potencia, aunque la negación del maquiavelismo no supone despreciar el justo empleo de la fuerza. Acota una política «moral y real» que resuelva la antinomia ética generada por circunstancias extraordinarias. En vano, dirá Aron, pues aunque las situaciones o la fortuna cambien de signo, la raíz del problema está en las imperfecciones consustanciales a la naturaleza humana (Aron, 1993b: 393-394). Lo que Maritain no tiene suficientemente en cuenta.

\section{MARITAIN 1943-1945: ES MORALMENTE LÍCITO REPRESALIAR AL ENEMIGO POR SUS ABOMINACIONES}

«Lo que le da a la vida política su grandeza sombría es que los hombres de Estado se ven abocados a ejecutar acciones que detestan porque, según los dictados de su alma y su conciencia, se sienten responsables del destino común». Con estas reflexiones termina Aron su respuesta a las consideraciones maritenianas de 1942 sobre el maquiavelismo (1993b: 395).

Maritain, fiándose de la providencia divina, está convencido de que no siempre se pueden escoger los medios de la acción política y todo su esfuerzo se dirige a «fundar la crítica del maquiavelismo sobre una base realista, no utópica». Así se lo hace saber a Aron en una carta fechada en Nueva York el 30 de septiembre de 1943 (Maritain, 1993). En ella le anuncia su apostilla, que se recogerá en Principes d'une politique humaniste (Maritain, 1945a: 197-198). Maritain se muestra de acuerdo con las observaciones de Aron sobre la dificultad para determinar a priori la casuística de la moral política. Pero eso no 
excluye lo esencial: una diferencia objetiva entre la astucia legítima y el engaño inmoral. Discernir entre una y otra es el objeto de la prudencia. Llegado el caso, decía Aron, hay que mancharse las manos para no sucumbir. Maritain, a su modo, lo va a corroborar. En su nota ad hoc y en sus discursos y mensajes de guerra. "Una política no-maquiavélica tiene la obligación de no hacer el mal, pero no la de hacer que reine la virtud» (Maritain, 1945a: 198). Por lo demás, no está en falta quien toma represalias, incluso terribles, contra un enemigo abominable, si las mismas se conducen con espíritu de justicia, no de crueldad. Maritain concluye que «la justicia política rechaza los medios condenados por la ética política auténtica, pero no acepta los dictados de una ética falsa y moralista que [...] ignora la naturaleza humana» (ibid.: 198).

En sus alocuciones radiofónicas para elevar la moral de sus compatriotas, afirma Maritain que la guerra es el fruto envenenado del olvido de Dios, pero advierte, no obstante, que «cuando la guerra se hace presente, los hombres de buena voluntad deben combatir hasta el fin por la justicia» (1945b: 105). La guerra contra Alemania, nación cazada en la «trampa del diablo» de un maquiavelismo que se vuelve contra ella (ibid:: 163), hay que ganarla. Invoca el realismo heroico de las democracias conscientes de la dimensión espiritual del combate. También su naturaleza «conservadora», paradoja impulsada por una lucha contra el nihilismo que amenaza la herencia espiritual de la civilización cristiana. Después de la victoria militar, sin embargo, caduca la virtud de semejante "posición conservadora». En 1939 Maritain había interrogado a Aron sobre el mismo problema: "¿Mantendrá la democracia su carácter conservador o adoptará un carácter revolucionario?». La respuesta de Aron, antes y después de la guerra, es inequívoca: toda democracia es conservadora.

\section{MARITAIN 1951: LA FUERZA SUPREMA ESTÁ EN LA JUSTICIA}

En su estudio sobre el fin del maquiavelismo se refería Maritain al gran problema de la liquidación de un Estado, pues a diferencia de la persona, una nación o una organización política no tiene un alma inmortal. Un mártir ganará el cielo, pero un Estado cuyos ciudadanos pongan la otra mejilla antes de ser pasados por las armas, no, simplemente "ha dejado de existir». Por eso «es un escarnio consolar a los franceses pidiéndoles que acepten la destrucción o el sometimiento de su patria hablándoles de la Francia eterna» (Maritain, 1945a: 173). Una nación pertenece al orden natural, temporal y terrestre. Aunque los medios justos tienden a la conservación de los Estados, el maquiavelismo puede eventualmente destruirlos. A fin de cuentas, «las naciones y las civilizaciones son mortales por naturaleza» (ibid.: 187). En tal caso, otra generación, otro pueblo u otra civilización pueden esperar el fruto engendrado por 
las buenas acciones que fracasaron. Aunque esa recompensa no llegue nunca, una cosa es segura para Maritain: «El mal infligido [a un pueblo aniquilado] introduce un principio oculto de autodestrucción en la médula de los conquistadores» (ibid.: 203). La violencia, dirá unos años después en The Man and the State, da la medida de la debilidad de un Estado; la justicia, en cambio, la de su fortaleza suprema (1953: 55). Afina en esta obra las notas realistas de su antimaquiavelismo: «[...] el miedo a ensuciarse penetrando en el contexto de la historia no es virtud, sino un medio de esquivar la virtud» (ibid:: 57). Maritain parece justificar su consentimiento al mal estalinista, aliado de las democracias occidentales, durante la Segunda Guerra Mundial.

\section{ARON 1982: NO SE PUEDE PRESCINDIR DEL MAQUIAVELISMO MODERADO}

En 1982 Aron ya no intenta contradecir las tesis maritenianas de los años cuarenta, solamente añade algunas notas a los elementos del diálogo en los que la posición de Maritain parece más cercana a la suya. En su comunicación a la Unesco, Aron acota claramente sus respectivas posiciones: él, sociólogo, piensa como historiador; Maritain, filósofo, como metafísico. Indiferente a los designios inescrutables de la Providencia, Aron recalca que en la situación extrema no se puede rechazar el maquiavelismo moderado. Es su última palabra: "Cuando una nación pasa por el trance de una guerra civil o del terrorismo que amenaza su existencia, lo que para muchos filósofos políticos constituye el mal absoluto, resulta de todo punto necesario reconstruir el Estado y eso no se consigue sin la policía, sin el ejército y sin cometer ciertas fechorias» (1993c: 431).

\section{DE MASTINES Y DE ZORROS}

La sagacidad de Maquiavelo ha desvelado un terrible secreto: para salvar a la nación hay a veces que perder el alma. Lo cual, por otro lado, no parece incompatible con el punto de vista expuesto por Jesús según san Mateo, el más político de los evangelistas. "El que pierda su vida por mí, la hallará» (Mateo, 16, 25). Jesús, cuyos silencios suelen ser elocuentes, no ha dicho que quien pierda una ciudad por la causa del Evangelio, salvará su alma, lo que deja, finalmente, un espacio a la acción temporal del político y el intelectual cristianos (Maritain, 1930: 72-73).

Maritain y Aron son conscientes de este «margen de maniobra» del político, cristiano o no, sometido a todo tipo de antinomias prácticas, así como de la aceptación por este del imprescriptible papel de la fuerza en la historia, algo 
imposible de ocultar. Después de todo, como escribe el católico de Estado Jérémie Ferrier, «el Rey no tiene la espada por nada. La tiene justamente para castigar a aquel que perjudica a un súbdito: así, él la ejerce con mayor justicia, cuando alguien pretende hacer daño a su Estado» (1626: 12; Molina Cano, 2013b: 28). Esa consciencia hace de Maritain un escritor político con ribetes si no maquiavelianos o metapolíticos ${ }^{17}$, sí maquiavelistas, incluso maquiavélicos; de Aron, un maquiavelista moderado.

\section{LA GUERRA DE ESPAÑA Y LA BATALLA DE FRANCIA EN EL COMPROMISO POLÍTICO MARITENIANO}

Maritain, sumamente crítico con el maquiavelismo, lo considera una escuela de tiranía y una doctrina autodestructiva a largo plazo e idéntico al realismo político, doctrina que en la Francia del siglo XX porta la marca de Charles Maurras ${ }^{18}$. Insistentemente dirá Maritain que «el maquiavelismo no triunfa jamás», presuponiendo que los arcanos insondables de la providencia divina están de parte de los sistemas políticos occidentales en su lucha contra las tiranías totalitarias. Esto, dicho en los momentos más bajos de Occidente, en plena Segunda Guerra Mundial, resulta de un patetismo extraordinario, aunque tiene mérito. Pero una cosa es la doctrina de Maquiavelo y otra muy distinta el maquiavelismo de los contemporáneos en sus dos versiones: el maquiavelismo absoluto y el maquiavelismo moderado. El maquiavelismo, ciertamente, ni siquiera atenuado o moderado, le parece a Maritain susceptible de ser utilizado por los regímenes demoliberales, pues toda forma de maquiavelismo, aun empleado como expediente provisional, le parece que conduce por una pendiente natural, inexorablemente, al maquiavelismo absoluto que no conoce límites.

La naturaleza de los compromisos políticos personales de Maritain parece mostrar, sin embargo, una contradicción entre el rechazo de principio de toda conducta taimada o ladina en política, maquiavélica o maquiavelista en sentido estricto o aun cínica, y su posicionamiento concreto ante los acontecimientos políticos, tal vez no del todo irreprochable. Es el caso de

17 Que los tiene también, sin duda. "La filosofía política no es ni de derechas ni de izquierdas; simplemente debe ser veraz» (Maritain, 1941a: 81).

18 Charles Maurras es para Jacques Maritain el modelo de un inane realismo político. Para Raymond Aron, en cambio, la expresión, junto a Alain, de un modo ideológico de pensar periclitado. Aun así, al margen de sus ideas, ligadas al periodo histórico que les toca vivir, Aron reconoce que se encuentran en Alain y Maurras «ciertas verdades permanentes» (1997: 31). 
sus recriminaciones contra los católicos españoles hostiles a la Segunda República y partidarios del bando nacional y de la Cruzada, de la que Maritain abomina en su famoso prólogo al libro de Alfredo Mendizábal sobre Los orígenes de una tragedia (2013) o, en otro contexto, contra Antoine de Saint-Exupéry por su llamamiento radiofónico «D’abord la France» a favor de la unión de los franceses, publicado a continuación en The New York Times Magazine de 29 de noviembre de 1942 bajo el título: «An open letter to Frenchman everywhere» ${ }^{19}$. La guerra de España y la batalla de Francia le abocan a tomar partido y a no permanecer neutral confiando sin más cautelas en el trabajo de la Providencia. A veces, dice entonces Maritain, es necesario juzgar y decidirse, laborar y mancharse las manos en el tiempo político por excelencia: el de la necesidad y los términos perentorios. Pues «la guerra continúa y hay que ganarla» (Maritain, 2000b: 228). Parece un cordero que quisiera convencer a los lobos. Pero solo lo parece.

En Maritain hay un maquiavelista que se ignora, aunque llame a su humanismo «realismo [político] de la Encarnación», «el único realismo verdaderamente real» (1941b: 135). Su actitud ante la guerra de España y la batalla de Francia son el ejemplo de un compromiso político, tal vez no cristiano en sentido estricto, pero indudablemente orientado a la obtención de los frutos de la victoria ${ }^{20}$.

\section{LA IMAGINACIÓN DEL DESASTRE ARONIANA}

El político baqueteado sabe ponerse siempre en lo peor, pues únicamente así, como solía recordar Julien Freund, se da los medios para conjurar el mal de la república (Freund, 1983: 363). Afrontar las dificultades o las amenazas políticas (envisager le pire) no significa, según el polemólogo francés, practicar una política resignada o derrotista (la politique du pire), sino

19 A. de Saint-Exupéry no se considera juez de sus compatriotas, cuyo sufrimiento carnal está por encima de todo. No desea seguir a De Gaulle contra otros franceses: su posición es la de un apolítico que llama al sacrificio personal y vislumbra para él un «túmulo apacible en algún pequeño cementerio del norte de África» (Saint-Exupéry, 2000: 213).

20 Lo mismo podría decirse de su anatema contra el estalinismo tras descubrirse el Pacto Ribbentrop-Molotov, crítica feroz transformada después en su silencio calculado dada la contribución soviética a la derrota de Alemania (Maritain, 1945b). Durante algún tiempo, los aliados necesitaron de los pesados medios carnales del totalitarismo soviético, una fuerza homicida y necrófila (Maritain, 1940: 12, 63-69). El oportunismo de Maritain en esta tesitura — su indulgencia hacia la Unión Soviética- lo pone de manifiesto y lo explica Raymond Aron (1983: 153). 
ver y meditar sin prejuicios para anticiparse a los acontecimientos, pues no hay peor política que la política de lo mejor (la politique du mieux). Michael Oakeshott lo llama "política escéptica» o "actitud conservadora» (1998: 58-64; 2009). Y Carlo Gambescia estar y aun vivir a guardia dei fatti (2009: 66; 2015: 44, 203). En situaciones extremas puede el político verse forzado a servirse incluso de medios inmorales o ilegítimos para defender la ciudad. De este modo, «todo aquello que se persigue a través de la acción política [...] pone en peligro la salvación del alma», según decía Max Weber en su famosa conferencia muniquesa de 1919 sobre la política como vocación o tarea (1986: 174). Aron, tocado por la imaginación del desastre, rasgo esencial del carácter del realista político (Molina Cano, 2015a: 21) ${ }^{21}$, sabe que no siempre se pueden elegir los medios de la acción política. No hay elección en las situaciones extremas. Si en 1939 advierte a las democracias para que no cedan en su entusiasmo frente al totalitarismo nacionalsocialista, en 1951 clama para que la voluntad de victoria de los occidentales no se achante y supere a los estalinistas (Aron, 1951: 9).

La actitud de Aron, netamente maquiavelista, es considerada por alguno de sus comentadores como una "debilidad [...] muy puntual» y pasajera, incluso como un mito (Freymond, 1993: 50-51). En realidad se trata de la fortaleza de un converso a la política realista que sabe contemporizar en política. Es el propio Aron quien se reconoce a sí mismo como un maquiavelista moderado (Molina Cano, 2013a: 57; Audier, 2005: 71 y 87).

En la obra de Azorín se encuentra muy bien apuntado el arquetipo de un escritor político católico, cuya caracterización, curiosa e inesperadamente, se adapta a los dos filósofos franceses objeto de este estudio como un guante y sin violentar su pensamiento ${ }^{22}$. En su extraordinario y pequeño libro El político,

21 El realismo político es más un método o una forma de pensar que una doctrina (Benoist, 1907: 4; Aron, 1993d: 110). Charles Benoist tiene, pues, buenas razones para estudiarlo desde una perspectiva psicológica y escribir, según él mismo dice en el Avertissement del primer tomo de su obra sobre el maquiavelismo, un «ensayo de psicología histórica» (1907).

22 La confesión católica, en realidad, viene a subrayar aquí el conflicto permanente entre las prescripciones morales y las conveniencias políticas, lo cual también afecta a los escritores políticos liberales. En última instancia, para evitar cualquier impregnación religiosa del pensamiento aroniano, se podría reconducir el pensamiento del escritor levantino al concepto de un «liberal triste», consciente de las servidumbres y grandezas del régimen político representativo o, si se prefiere, democrático. El liberalismo triste o árquico, por oposición al neoliberalismo o liberalismo ridens, es aquel que tiene conciencia del fondo inmutable de lo político, conoce su ley y no se engaña sobre lo que cabe esperar. El liberal triste es un liberal 
escrito en 1908 como homenaje al político conservador y hombre de Estado Antonio Maura —estadista antes que político cristiano (Negro Pavón, 2000)_, sugiere Azorín que los grandes escritores políticos católicos nunca han sido unos cándidos ni unos pánfilos. Tampoco lo son los liberales árquicos (Gambescia, 2015). En nada son estos inferiores a los teóricos de la fuerza y de la astucia en política — representadas estas por el león y el zorro—. ¿o ha escrito también Gracián, como Saavedra Fajardo, Erasmo, Maquiavelo y Dante o, siglos antes, Plutarco y Cicerón, que «cuando no pueda vestirse uno la piel del león vístase la de vulpeja» (Gracián, 2000: 123; Saavedra Fajardo, 1999: 524-532; Erasmo, 1996: 43; Maquiavelo, 1998: 38; Dante, 1965: 152; Plutarco, 1987: 205; Cicerón, 1989: 25) ${ }^{23}$ ? En efecto, tanto en el antimaquiavelismo católico como en el liberalismo árquico hay una suerte de disimulo, aunque no simulación, pues esta sería pecado o, según la perspectiva, un atentado contra el régimen de tipo constitucional-pluralista (Aron, 1992b: 109219). Al rey Luis XI se Francia se atribuye el lema Qui nescit disimulare, nescit regnare [No sabe reinar quien no sabe disimular].

Las páginas de Azorín tienen toda la claridad que puede permitirse un político como él, frío pero tímido. En su opinión, que tan bien le cuadra a Maritain y a Aron, en último análisis no tan discrepantes el uno del otro, los fieles canes del realismo político (católicos romanos, liberales árquicos), en realidad «solemnes vulpejas disfrazadas con pieles de mastines», siempre se han burlado de los zorros maquiavélicos: «¿Por qué ladran y acosan estos viejos canes [católicos] a la vulpeja florentina? Diríase, al oír sus desaforados ladridos, que en el mundo no ha habido más que una vulpeja, y que ella [Maquiavelo] es la que nos ha traído todo el daño. No, [nada más falso,] los que proclaman que Maquiavelo ha enturbiado y perturbado el mundo están en un error. [...] Los canes que ladraban contra la vulpeja florentina eran [en realidad] bien leales y vigilantes, [pero estos canes no eran canes]. Si ladraban más clamorosamente que los demás lo hacían para que el señor y amo del cortijo no vislumbrase la artimaña» (Azorín, 1980: 59-60, 50).

escéptico del linaje que va de Edmund Burke a Carl Schmitt, Julien Freund, el propio Raymond Aron e Isaiah Berlin (Gambescia, 2015).

La misma complementariedad de la astucia y la fuerza está presente también en la tradición judía (Refael-Vivante, 2009). No existe, en cambio, en la tradición política india. En esta se prefiere siempre la fuerza a la astucia, si bien la fuerza debe modularse según el espacio y el tiempo, pues el perro vence al cocodrilo en la tierra y este a aquel en el agua, y el cuervo vence al búho de día, pero de noche es este quien se impone a aquel (Kautilya, 2003: 407-408). 


\section{Bibliografía}

Aron, R. (1951). Les guerres en chaîne. Paris: Gallimard.

- (1983). Mémoires. 50 ans de réflexion politique. Paris: Juillard.

- (1990a). L'homme contre les tyrans. En R. Aron. Chroniques de guerre. La France Libre, 1940-1945 (pp. 411-690). Paris: Gallimard.

- (1990b). Lâge des empires et l'avenir de la France. En R. Aron. Chroniques de guerre. La France Libre, 1940-1945 (pp. 691-1002). Paris: Gallimard.

- (1992a). Le spectateur engagé. Entretiens aves Jean-Louis Missika et Dominique Wolton. Paris: Julliard.

— (1992b). Démocratie et totalitarisme. Paris: Gallimard.

- (1993a). États démocratiques et États totalitaires. En R. Aron. Machiavel et les tyrannies modernes (pp. 173-191). Paris: Éditions du Fallois.

- (1993b). La querelle du machiavélisme. En R. Aron. Machiavel et les tyrannies modernes (pp. 383-395). Paris: Éditions du Fallois.

- (1993c). Sur le machiavélisme, dialogue avec J. Maritain (colloque à l'UNESCO en 1982). En R. Aron. Machiavel et les tyrannies modernes (pp. 426-435). Paris: Éditions du Fallois.

- (1993d). Pareto et le machiavélisme du XX siècle (pp. 110-122). En R. Aron. Machiavel et les tyrannies modernes (pp. 426-435). Paris: Éditions du Fallois.

- (1993e). Réflexions de politique réaliste. En R. Aron. Machiavel et les tyrannies modernes (pp. 379-383). Paris: Éditions du Fallois.

- (1993f). Le machiavélisme de Machiavel. En R. Aron. Machiavel et les tyrannies modernes (pp. 59-85). Paris: Éditions du Fallois.

- (1993g). La comparaison de Machiavel et Pareto. En R. Aron. Machiavel et les tyrannies modernes (pp. 86-109). Paris: Éditions du Fallois.

- (1993h), Machiavélisme et tyrannies. En R. Aron. Machiavel et les tyrannies modernes (pp. 123-160). Paris: Éditions du Fallois.

- (1993i). «Lectures» de Pareto. En R. Aron. Machiavel et les tyrannies modernes (pp. $275-$ 279). Paris: Éditions du Fallois.

- (1993j). Le machiavélisme, doctrine des tyrannies modernes. En R. Aron. Machiavel et les tyrannies modernes (pp. 192-202). Paris: Éditions du Fallois.

- (1994). Le message de Bernanos. Commentaire, 68, 913-919.

- (1997). Introduction à la philosophie politique. Démocratie et révolution. Paris: Le Livre de Poche.

— (2000). Préface. En A. de Sain-Exupéry. Écrits de guerre 1939-1944 (pp. 7-14). Paris: Gallimard.

Audier, S. (2005). Machiavel, conflit et liberté. Paris: Vrin.

Azorín (1980). El politico. Madrid: Espasa-Calpe.

Benoist, C. (1907-1936). Le machiavélisme. Paris: Plon.

Bernanos, G. (1984). Scandale de la vérité suivi de Nous autres, Français. Paris: Seuil.

Blahuta, J. P. (2008). Maritain, Machiavelli, and the problem of machiavellianism: Maritain's challenge to political leaders. Maritain Studies, XXIV, 57-70. 
Bouthoul, G. (1948). Huit mille traités de paix. Paris: Julliard.

Burnham, J. (1953). Los maquiavelistas, defensores de la libertad. Buenos Aires: Emecé.

Campi, A. y De Luca S. (ed.) (2014). Il realismo politico. Figure, concetti, prospettive di ricerca. Soveria-Mannellli: Rubbettino.

Churchill, W. S. (2016). Europa unida. Dieciocho discursos y una carta. Madrid: Ediciones Encuentro.

Cicerón (1989). Sobre los deberes. Madrid: Tecnos.

Dante (1965). La Divina Comedia. En Dante, Obras completas (pp. 21-534). Madrid: B.A.C.

De Rougemont, D. (1968). Journal d’une époque. Paris: Gallimard.

Erasmo de Róterdam (1996). Educación del príncipe cristiano. Madrid: Tecnos.

Fernández, G. F. (2004). El maquiavelismo en el pensamiento de J. Maritain. En E. Bambozzi y P. Baquero Lazcano (eds.). Jacques Maritain. Homenaje (pp. 103-112). Córdoba, Argentina: Ediciones de la Universidad Católica de Córdoba.

Ferrier, J. (1626). Le catholique d'État, ou Discours politique des aliances du Roy très-Chrestien, contre les calomnies des ennemies de son État. Paris: Joseph Bouillerot.

Freund, J. (1983). Sociologie du conflit. Paris: PUF.

(1986). L'essence du politique. Paris: Sirey.

(1987). Politique et impolitique. Paris: Sirey.

Freymond, R. (1993). Présentation. En R. Aron. Machiavel et les tyrannies modernes (9-56). Paris: Éditons du Fallois.

Gambescia, C. (2009). Metapolitica. L'altro sguardo sul potere. Piombino: Il Foglio. (2015). Liberalismo triste. Un recorrido de Burke a Berlin. Madrid: Encuentro.

Gentile, E. (2001). Le religioni della politica. Fra democrazie e totalitarismi. Roma-Bari: Laterza.

Gilson, É. (2013). Pour un ordre catholique. Paris: Parole et Silence.

Gracián, B. (2000). Oráculo manual y arte de prudencia. Madrid: Debate.

Kautilya (2003). Arthaśāstra. En R. P. Kangle (ed.). The Kauţilìya Arthaśāstra. Part II. An English Translation with Critical and Explanatory Notes. Delhi: Motilal Banarsidas Publishers.

Kussbach, E. (1991). Jacques Maritain über Machiavelli und den modernen Machiavellismus. En H. W. Kaluza, H. F. Köck y H. Schambeck (ed.). Glaube und Politik. Festschrift für Robert Prantner (pp. 53-64). Berlin: Duncker u. Humblot.

Lanux, P. de (2000). «Souvenirs de Pierre de Lanux». En A. de Saint-Exupéry. Écrits de guerre 1939-1944 (pp. 195-198). Paris: Gallimard.

Maquiavelo (1998). Il principe. En Maquiavelo. Tutte le opere storiche, politiche e letterarie (pp. 6-55). Roma: Newton.

Maritain, J. (1925). Antimoderne. Paris: Éditions de la Revue des Jeunes.

- (1926). Charles Maurras et le devoir des catholiques. Paris: Plon.

(1927). Primauté du spirituel. Paris: Plon.

(1930). Religion et culture. Paris: Desclée de Brouwer.

(1937). Du régime temporel et de la liberté. Paris: Desclée de Brouwer.

(1940). De la justice politique. Notes sur la presente guerre. Paris: Plon.

(1941a). Le crépuscule de la civilisation. Montréal: Éditions de l'arbre.

(1941b). Á travers le désastre. New York: Éditions de la Maison Française.

(1942a). The end of machiavellianism. The Review of Politics, 4 (1), 1-33. 
- (1942b). La fin du machiavélisme. Nova et Vetera. Revue Catholique pour la Suisse Romande, 17 (2), 113-145.

(1942c). Religion and Politics in France. Foreign Affairs, 20 (2), 266-281.

(1945a). Principes d'une politique humaniste. Paris: Paul Hartmann Éditeur.

(1945b). Messages 1941-1944. Paris: Hartmann.

(1945c). À travers la victoire. Paris: Hartmann.

(1947). Humanisme intégral. Paris: Aubier.

(1948). Tres reformadores: Lutero, Descartes, Rousseau. Madrid: EPESA.

(1953). L'homme et l'État. Paris: PUF.

(1966). Le paysan de la Garonne. Un vieux lä̈c sinterroge à propos du temps présent. Paris: Desclée de Brouwer.

- (1992). Aproches sans entraves. En J. Maritain y R. Maritain. Oeuvres complètes. Vol. XIII: 1968-1973 (pp. 415-1222). Fribourg-Paris: Éditions Universitaires \& Éditions Saint-Paul.

- (1993). Lettre de J. Maritain à Raymond Aron. En R. Aron. Machiavel et les tyrannies modernes (p. 425). Paris: Éditions du Fallois.

- (2000a). Problemas espirituales y temporales de un nuevo cristianismo». En B. Madariaga y C. Valbuena (eds.). La Universidad Internacional de Verano en Santander. Resumen de sus trabajos en el curso 1934 (pp. 227-236). Santander: UIMP.

- (2000b). Il faut parfois jugar. (À propos d'une lettre ouverte de Saint-Exupéry). En A. de Saint-Exupéry. Écrits de guerre 1939-1944 (pp. 221-229). Paris: Gallimard.

- (2013). Prefacio. En A. Mendizábal Villalba. Los orígenes de una tragedia. La política española desde 1923 hasta 1936 (pp. 3-35). Madrid: CEPC.

Mendizábal Villalba, A. (2013). Los orígenes de una tragedia. La política española desde 1923 hasta 1936. Madrid: CEPC.

Molina Cano, J. (2000). Julien Freund, lo politico y la política. Madrid: Sequitur.

- (2004). Julien Freund, del realismo político al maquiavelismo. Anales de la Facultad de Ciencias Sociales de La Plata, 11-24.

- (2013a). Raymond Aron, realista politico. Madrid: Sequitur.

- (2013b). Diego Saavedra Fajardo, realista político. Una invitación a los estudios saavedrianos en Chile. Ius Publicum, 30, 27-38.

— (2014). El realismo, una forma-límite del pensamiento político. En A. Campi y S. de Luca (eds.). Il realismo politico. Figure, concetti, prospettive di ricerca (pp. 81-99). Soveria-Mannelli: Rubbettino.

— (2015a). El realismo político. En E. Anrubia y Á. de Rueda (eds.). Felicidad y conflicto. Filosofías para el mundo de mañana (pp. 15-27). Granada: Comares.

- (2015b). La querelle du machiavélisme: Jacques Maritain et Raymond Aron (19391945). En J.-L. Clément. La liberté à l'époque de Jacques Maritain 1931-1939 (pp. 93-105). Paris: Les Indes Savantes.

Molnar, T. (1999). Jacques Maritain: personalidad proteica del siglo xx. Verbo, 373/374, 253-263.

Negro Pavón, D. (2000). Don Antonio Maura, hombre de Estado. Homenaje a don Antonio Maura (67-77). Madrid: Instituto de España. 
- (2009). Una respuesta ateiopolítica al silencio de Dios. Anales de la Real Academia de Ciencias Morales y Políticas, 86, 543-584.

Oakeshott, M. (1998). La política de la fe y la política del escepticismo. México: Fondo de Cultura Económica.

- (2009). La actitud conservadora. Madrid: Sequitur.

Oro Tapia, L. R. (2013). El concepto de realismo político. Santiago de Chile: RIL Editores.

Plutarco (1987). Obras morales y de costumbres. Moralia III. Madrid: Gredos.

Pocok, J. G. A. (2008). El momento maquiavélico. El pensamiento político florentino y la tradición republicana atlántica. Madrid: Tecnos.

Portinaro, P. P. (1999). Il realismo politico. Roma-Bari: Laterza.

Portuondo Pajón, G. L. (2009). Historia, antropocentrismo, maquiavelismo. La perspectiva filosófica de Jacques Maritain. Dikaiosyne, 22 (12), 116-130.

Refael-Vivante, R. (2009). Of Lions and Foxes: Power and Rule in Hebrew Medieval Fables. Revista Paz y Conflictos, 2, 24-43.

Rougier, L. (1929). La mystique démocratique. Ses origines, ses illusions. Paris: Flammarion.

Saavedra Fajardo, D. (1999). Empresas politicas. Madrid: Cátedra.

Saint-Exupéry, A. (1997). Pilote de guerre. Paris: Gallimard.

- (2000). Écrits de guerre 1939-1944. Paris: Gallimard.

Schall, J. V. (1998). Jacques Maritain: the Philosopher in Society. Lanhman: Rowman and Littlefield Publishers.

- (1999). Was Maritain a Crypto-Machiavelian? En Brendan Sweetman (ed.). The Failure of Modernism. The Cartesian Legacy and Contemporary Pluralism. Mishawaka: American Mariatin Association.

Sérant, P. (1978). Les dissidents de L'Action Française. Paris: Copernic.

Spengler, O. (1998). La decadencia de Occidente. Bosquejo de una morfologia de la historia universal. Madrid: Espasa-Calpe.

Tabet, X. (2013). La «querelle de Machiavel» en France au XIXe et XXe siècles. Annuaire de l'Institut Michel Villey, 5, 243-263.

Tellis, A. J. (2005). Introduzione al realismo politico. La lunga marcia verso una teoría scientifica. Roma: Marco Editore.

Viotto, P. (2003). Jacques Maritain. Dizionario delle opere. Roma: Città Nuova.

- (2009). Grandi amicizie. I Maritain e i loro contemporanei. Roma: Città Nuova.

Weber, M. (1986). La política como vocación. En M. Weber, El político y el científico (pp. 81-179). Madrid: Alianza Editorial. 